Case Reports
in Dermatology

\title{
Successful Treatment of Hard Corns in Two Patients Using Microwave Energy
}

\author{
Ivan R. Bristow ${ }^{\mathrm{a}} \quad$ Christopher J. Webb ${ }^{\mathrm{b}}$

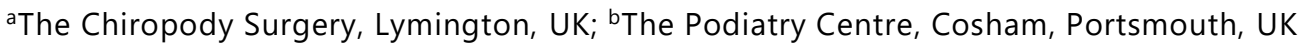

\section{Keywords}

Plantar corns · Microwave energy · Pain

\begin{abstract}
Corns are a common foot problem accounting for nearly half of all problems seen within podiatry and chiropody clinics. Hard corns are concentrated areas of hyperkeratosis within the stratum corneum, typically found on the weight-bearing (plantar) surfaces of the feet. For many patients, they are a source of pain and have been shown to negatively affect a patient's activity and quality of life. Most of the currently available treatments are short-lived in their effectiveness, with corns frequently being recurrent, requiring repeated visits to remove the painful lesions. The use of handheld microwave devices indicated for surface applications has demonstrated effectiveness in clearing recalcitrant plantar warts and significantly reducing the pain associated with them. The authors report 2 cases of patients with persistent and painful plantar corns who underwent microwave treatment of their plantar corns with a successful, lasting reduction in pain levels after the intervention. Further work is required to fully assess the potential of this treatment modality in the management of painful plantar corns.
\end{abstract}




\section{Case Reports in Dermatology}

Case Rep Dermatol 2020;12:213-218

DOI: 10.1159/000509791

C 2020 The Author(s). Published by S. Karger AG, Basel www.karger.com/cde

Bristow and Webb: Painful Plantar Corns Successfully Treated Using Microwaves

\section{Introduction}

Corns are a common foot problem thought to affect between 10 and $48 \%$ of adults [1, 2]. Typically, they present as hard, yellow hyperkeratotic lesions, located in areas of the foot subjected to pressure. Their exact aetiology remains unclear; however, the intermittent forces generated during locomotion and by shoe wear are known to increase shear and frictional forces across the foot, which in turn leads to the development of thickening of the stratum corneum (hyperkeratosis), which may develop into symptomatic corns - most frequently located under the metatarsal heads and on the lateral side of the fifth toe.

Their presence can lead to pain, a decrease in physical function and a reduction in the patient's quality of life [3]. Smokers are known particularly to develop painful plantar lesions [4]. Traditional treatment of plantar corns focuses on elimination of the causative factors, where possible, but for many patients they can take a chronic course. Within chiropody and podiatry clinics, removal of the corn using a scalpel (enucleation) is a favoured procedure which has been shown to give immediate short-term relief of pain [5]. Consequently, for many patients, due to the recurrent nature of corns, repeat visits to the podiatrist/chiropodist for treatment are necessary to reduce the pain associated with them.

In a previously published study, a handheld microwave device indicated for the treatment of surface skin lesions was shown, in a cohort of 32 adult patients, to resolve stubborn plantar warts. One finding from this work suggested a significant decrease in pain levels associated with their warts whilst undergoing treatment with microwaves [6]. Histologically, corns and warts both represent potentially painful hyperkeratotic lesions.

\section{Case Presentation}

Patient A was a 50-year-old construction worker. His medical history showed occasional migraines, for which he took sumatriptan $(25 \mathrm{mg})$, but he was otherwise in good health. He had smoked 10 cigarettes a day for many years. He had a history of two small, plantar corns on his left foot which had been present for years (Fig. 1). He was receiving monthly podiatry appointments for scalpel reduction of the corns to relieve the pain. Prior to the current treatment regime, he had tried prescription insoles to redistribute pressure away from the painful areas of the foot and the application of salicylic acid corn plasters. The latter had led to irritation of the skin, so consequently it was discontinued by the patient.

Following a discussion with the patient and consent, it was decided to embark on a course of microwave treatment using the SWIFT ${ }^{\circledR}$ microwave device (Emblation, UK). A course of treatment was proposed using microwave treatment given at monthly intervals for up to 4 months. At each appointment visit, prior to debridement, both plantar corns were cleaned using chlorohexidine gluconate in $70 \%$ alcohol and enucleated with a scalpel. The microwave device was then placed onto each of the two corns, and $10 \mathrm{~W}$ of energy was delivered for $2 \mathrm{~s}-$ a total of $20 \mathrm{~J}$ of energy was delivered into each lesion at each visit. At each visit, the patient was also asked to rate the pain in the week prior to treatment on a scale of $0-10$ (with $0=$ no pain, $10=$ the worst pain imaginable).

Prior to the first application of treatment, the patient had rated the pain as 6 out of 10 . On subsequent visits the pain score reduced to a score of 1 . A month after the fourth application of microwaves, the patient reported no pain (score of 0 ) from the corn in the previous week. After completion of treatment, he extended his appointment intervals to 12 weeks with no active further treatment. At his review 6 months after the last treatment, he reported that 


\section{Case Reports in Dermatology}

Case Rep Dermatol 2020;12:213-218

DOI: $10.1159 / 000509791$

(c) 2020 The Author(s). Published by S. Karger AG, Basel www.karger.com/cde

Bristow and Webb: Painful Plantar Corns Successfully Treated Using Microwaves

although they were still present, the corns were no longer painful (Fig. 2). He was advised to return should they become painful again, but did not return to the clinic after this appointment.

Patient B was a 77-year-old female with a painful corn of 20 years duration on the lateral apex of her third toe (Fig. 3). She was in good health and receiving no medication. Her corn was being treated with fortnightly scalpel debridement by her podiatrist, but despite this the patient reported the pain as a constant problem affecting her daily activities. Following a discussion with the patient, a course of microwave treatment was suggested. Prior to treatment, the patient had rated the pain from her corn as 7 out of 10 ( 0 being no pain, 10 the worst pain imaginable). The lesion was cleaned with $70 \%$ alcohol and underwent scalpel debridement. Following this, the corn was treated using microwaves - a single application of $8 \mathrm{~W}$ for $2 \mathrm{~s}, 5$ times. She was re-booked to return after 2 weeks. At this appointment, she reported a significant pain reduction (to 4 out of 10). A subsequent repeat treatment of $8 \mathrm{~W}$ for $2 \mathrm{~s}$, applied 5 times, was carried out. Four weeks later, her pain level had reduced to 1 out of 10 and the treatment with microwaves was repeated ( $8 \mathrm{~W}$ applied to the corn for $2 \mathrm{~s}, 5$ times). The patient was reviewed after 3 treatments and reported no further pain from the lesion (Fig. 4). At 6 months, although still present, the corn was still entirely pain free.

\section{Discussion and Conclusion}

The use of a handheld microwave device in the treatment of plantar warts showed a clearance rate of nearly $76 \%$ in adults with recalcitrant lesions. The data from this work highlighted how following treatment of painful warts using microwaves, there was a significant reduction in reported pain scores in the majority of participants [6]. Both corns and plantar warts are hyperkeratotic lesions of the epidermis exhibiting similar features - hyperkeratosis of the stratum corneum and pain are frequently associated with their presence.

Microwaves are a form of energy within the electromagnetic spectrum (300 MHz to 300 $\mathrm{GHz}$ ). A review of the effects of electromagnetic energy on human tissue has reported a number of such effects, including pain relief, which may contribute to the positive outcome observed in these patients [7]. Despite the reduction in pain, both our patients remained with pain-free corns, suggesting that the effect was likely based on alteration of the local pain mechanisms rather than on pain relief through eradication of the lesions. Even though the exact mechanism is unknown, there are several theories which may help explain the observed effect.

Research has shown that in peripheral nerve fibres, raising of the skin temperature is accompanied by an increase in nerve conduction velocity with a concomitant decrease in sensory latency. The nerve conduction velocity increases, and this is thought to be related to nerve denervation or an increase in the pain threshold [8]. It is known that use of this microwave device on skin can increase local skin temperatures in the hyperthermic range of $46^{\circ} \mathrm{C}$ [9], which may give rise to localised nerve denervation and a subsequent reduction in pain.

A review of the effects of pulsed electromagnetic fields has been undertaken, and at a cellular level, it has been shown how the modality causes an increase in calcium binding to calmodulin, which in turn promotes nitric oxide release, which induces the effect of pain relief. In addition, levels of the proinflammatory cytokine IL-1 $\beta$ have been shown to be lower in those patients receiving electromagnetic energy treatment [10]. This cytokine has been shown to be stimulatory in the induction of pain following nerve injury. 


\section{Case Reports in Dermatology}

However, further work is required to assess this effect seen with microwaves on a larger study population as a potential modality for the treatment of painful plantar corns.

\section{Statement of Ethics}

This work complies with the guidelines for human studies and was conducted ethically in accordance with the World Medical Association Declaration of Helsinki. The patients have given their written informed consent to publish their case (including publication of images).

\section{Conflict of Interest Statement}

I.R.B. is a consultant for Emblation Limited. C.J.W. has no conflicts of interest to declare.

\section{Funding Sources}

The manufacturer of the microwave device has provided payment for the article processing fee for this article.

\section{References}

1 Burzykowski T, Molenberghs G, Abeck D, Haneke E, Hay R, Katsambas A, et al. High prevalence of foot diseases in Europe: results of the Achilles Project. Mycoses. 2003 Dec;46(11-12):496-505.

2 Farndon L, Vernon W, Parry A. What is the evidence for the continuation of core podiatry services in the NHS: a review of foot surveys. Br J Podiatr. 2006;9:89-94.

3 Farndon L, Concannon M, Stephenson J. A survey to investigate the association of pain, foot disability and quality of life with corns. J Foot Ankle Res. 2015 Dec;8(1):70.

4 Merrill TJ, Vena V, Rodrigues LA. Relationship between smoking and plantar callus formation of the foot. Podiatry Insitute; 2012.

5 Gijón-Noguerón G, García-Paya I, Morales-Asencio JM, Jiménez-Cebrián A, Ortega-Ávila AB, Cervera-Marín JA. Short-term effect of scalpel debridement of plantar callosities versus treatment with salicylic acid patches: the EMEDESCA randomized controlled trial. J Dermatol. 2017 Jun;44(6):706-9.

6 Bristow I, Lim WC, Lee A, Holbrook D, Savelyeva N, Thomson P, et al. Microwave therapy for cutaneous human papilloma virus infection. Eur J Dermatol. 2017 Oct;27(5):511-8.

7 Guo L, Kubat NJ, Isenberg RA. Pulsed radio frequency energy (PRFE) use in human medical applications. Electromagn Biol Med. 2011 Mar;30(1):21-45.

8 Kelly R, Beehn C, Hansford A, Westphal KA, Halle JS, Greathouse DG. Effect of fluidotherapy on superficial radial nerve conduction and skin temperature. J Orthop Sports Phys Ther. 2005 Jan;35(1):16-23.

9 Bristow IR, Ardern-Jones M. Treating verrucae effectively with microwave energy - are we getting warmer? Podiatry Now. 2017;20(6):21-3.

10 Strauch B, Herman C, Dabb R, Ignarro LJ, Pilla AA. Evidence-based use of pulsed electromagnetic field therapy in clinical plastic surgery. Aesthet Surg J. 2009 Mar-Apr;29(2):135-43.

The authors contributed equally to the manuscript 


\section{Case Reports in Dermatology}

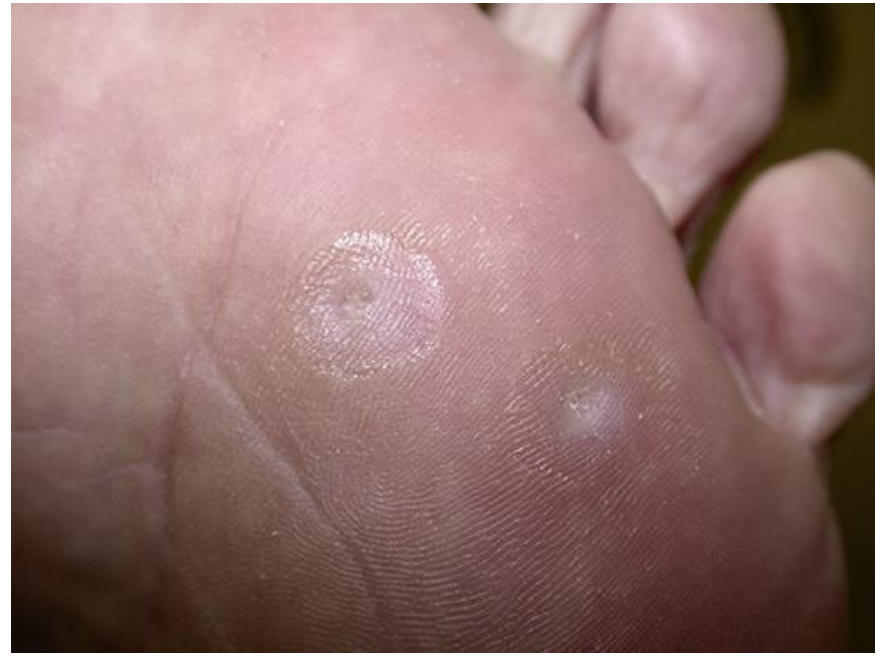

Fig. 1. Patient A: plantar corns prior to microwave treatment.

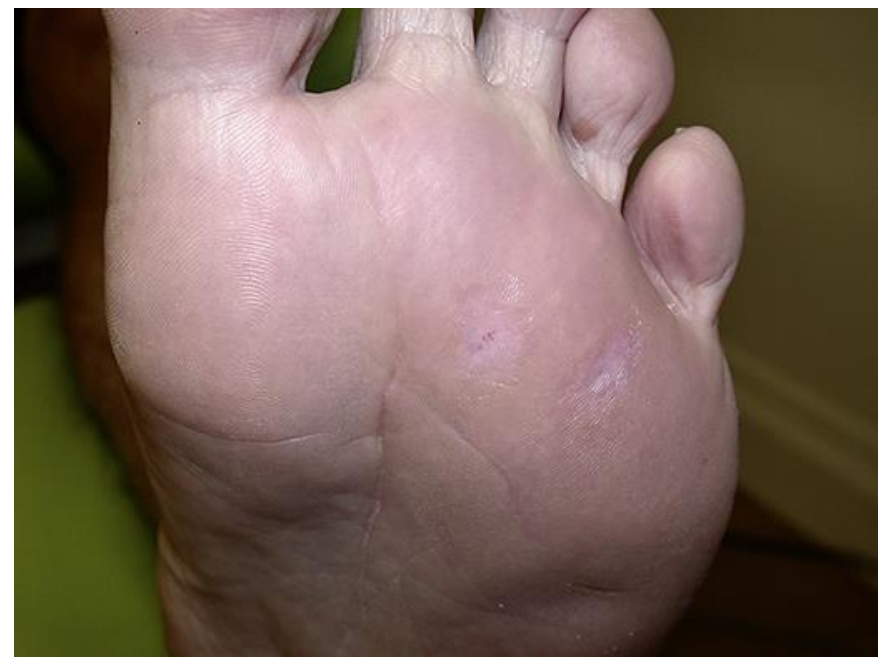

Fig. 2. Patient A: plantar corns at the 6-month review after completion of treatment. 


\section{Case Reports in Dermatology}

\begin{tabular}{l|l}
\hline Case Rep Dermatol 2020;12:213-218 \\
\hline DOI: 10.1159/000509791 & $\begin{array}{l}\text { ( ) 2020 The Author(s). Published by S. Karger AG, Basel } \\
\text { www.karger.com/cde }\end{array}$ \\
\hline
\end{tabular}

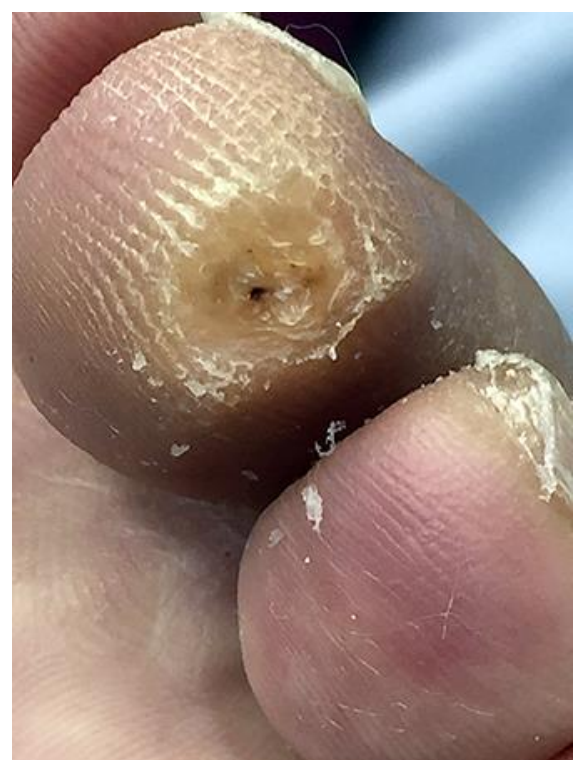

Fig. 3. Patient B: apical corn at presentation.

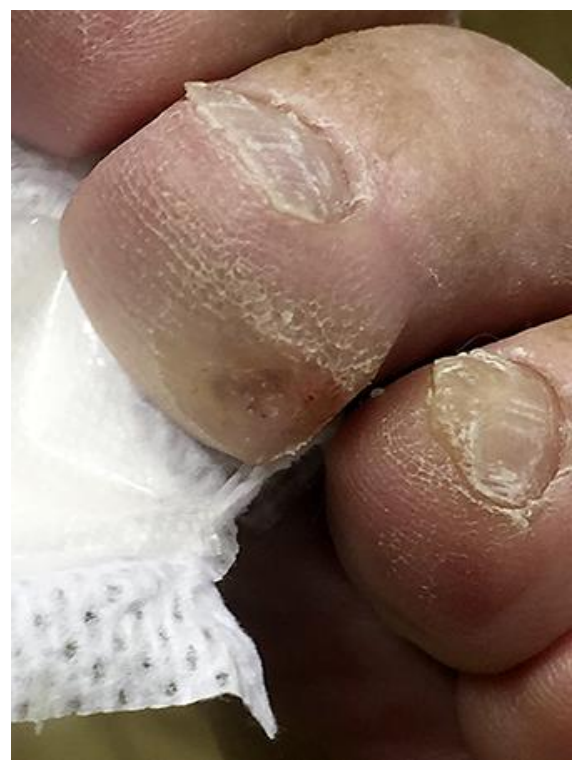

Fig. 4. Patient B: after 3 microwave treatments. 